\title{
Harold Cohen's Artificial Intelligence Paradigm for Art Making: An Overview
}

\section{Mary Leigh Morbey}

Nicholas P. Negroponte (1976) of the MIT Media Laboratory observed that "rarely have two disciplines joined forces seemingly to bring out the worst in each other as have computers and art." The computer generated imagery of acclaimed Modern artist Harold Cohen is one exception to this observation.

Harold Cohen is known for his English Abstract Expressionist paintings of the 1960s. His works Tribune of 1962 and Before the Event (Fig. 1) of 1963 are owned by the Tate Gallery, London. Before the Event is placed in a prominent location in a smaller Tate gallery that focuses on Modern British art of the 1960s. In 1965 Cohen's work was included in Documenta III in Kassel, Germany, and in 1966, along with four other artists, he was chosen to represent Great Britain at the XXIII Venice Biennale and sent the painting Pastoral of 1965. Michael Compton (1983) of the Tate Gallery comments on Cohen's artistic success: "From about 1952 until 1968 Harold Cohen built up a reputation as painter equal to that of any British artist of his generation."

In 1968 Cohen spent one year as a visiting professor at the University of California at San Diego. Early in his visit he became involved with the computer and in subsequent years with a group of computer scientists at Stanford University working in artificial intelligence. This involvement led him to change from canvas painting to art making on the computer, using canvas, ink, and paint as "primary output" media (Cohen, 1992). For the last two decades his work has been mainly computer generated. This imagery has received only a small amount of serious criticism from visual art critics and art historians. This lack of criticism contrasts sharply with the over two hundred articles written about Cohen's abstract expressionist paintings. Alan Bowness (1983), director of the Tate Gallery, assessed Cohen's career in a 1983 Tate Gallery exhibition catalogue of Cohen's work.

Harold Cohen first made his reputation as an abstract painter in London in the 1950s, and the Tate Gallery owns two important works of 1961 and 1962 . The artist's move to the west coast of the United States shortly afterwards and his abandoning of easel paintings for more experimental media has meant that we have lost sight of one of the outstanding talents of our generation. 


\section{Research Problem}

My dissertation study on Harold Cohen traces, from the vantage points of art history and art criticism, the development of his career from his art training at the Slade School of Art, University College, London, England, through his success as a painter, to his more current computer generated imagery. The project describes Cohen's development, delineates a central theme that unifies the bodies of his work, and thus fills in the historical gap between the extremely well documented paintings of the 1960 s and the minimal art historical and art critical discussion of his computer generated imagery rendered since 1968.

\section{Methodology}

For the study 1 use an interdisciplinary, contextual, art historical approach that incorporates the examination of Cohen's Imagery, its theoretical and historical contexts, and the situations in which the work is presented. I delineate the art historical context of Cohen's work, including a chronological discussion of ideas and styles from his early years as an art student at the Slade School of Art, through his modernist paintings, to his current computer generated imagery. Working from an interdisciplinary viewpoint, centering on context, I look at style analysis from art history, interpretation from art history and art criticism, history and theory of developments of modern art, contemporary art, and computer related art, and theories of artificial intelligence from computer science, in order to reach a fuller understanding of Cohen's contribution to and place in the history of art.

I employ Barrett's (1990) three category model for contextual analysis to organize the diverse components that comprise Cohen's basis for art making on canvas and computer. Internal context considers the art work, describing medium, subject matter, and form, and the interrelation of the three (Barrett, 1990). Original context is history, including the history of Cohen and his works, art history, social history, and histories of computer related art and the artificial Intelligence vein of computer science (Barrett, 1990). External context is the circumstances in which Cohen's art works are presented, whether it be the work on a gallery wall or the critic's review of the work, and includes those who chose to critique his painting and ignore the computer imagery (Barrett, 1990). The tri-focal contextual approach provides a method of analysis of the diverse areas of Cohen's art making. Barrett's contextual model assists the structuring of my analysis of Cohen and helps me more fully make connections between Cohen's art making on canvas and on the computer.

I employ this methodology to consider, first, Cohen the painter, by tracing his training at the Slade School of Art, locating him within the development of Modern English art, and noting his contribution. Second, I relate the history of art making with computers and place Cohen's contribution within it. A review of his incorporation of artificial intelligence clarifies the 
relationship of his art making to artificial intelligence and the computer. Third, I look at commentary on Cohen by art critics, art historians, and computer science and artificial intelligence experts. Fourth, I analyze Cohen's canvas and computer imagery. Fitth, I present Cohen through his writings and interviews, and I discuss his art making on canvas, his move to the computer, and computer generated imagery. Finally, I draw an interpretative conclusion (phrasing?) about Cohen taking into account what he says, what critics say about his work, my viewpoint of his work, and I suggest some implications of this study of Cohen's work for the field of art education.

\section{A Unified Interpretation of Cohen}

The study substantiates my thesis of Harold Cohen's art making as a unified whole, thus resolving the problem of the historical gap between the modem paintings of the 1960 s and the computer generated imagery of 1968 through the present. My interpretation aligns Cohen with art historian Rudolf Wittkower's concern to discover how the visual symbol (mark) in art yields meaning to the viewer, and provides an underlying link that joins the seemingly disparate stages in Cohen's art making.

This interpretation can be substantiated by tracing Cohen's research on how visual structure (mark making) generates, or yields, meaning to the viewer. His investigation began during his student days at the Slade School of art while studying with Wittkower, continued throughout his years of artistic acclaim in the 1960s, and led to the development of the computer program artist AARON. The study lays bare Cohen's growing dissatisfaction with his painting of the 1960s that led to an intellectual restlessness. He sensed that although he had been painting for twenty years he did not know much more about painting than when he began (Cohen, 1986). His interest was with notions of representation in the broad sense of making marks that other people believe to have meaning, and this led him to seek out a way to build a theory of representation that explains this activity (Cohen, 1986). His serendipitous introduction to the computer, in conjunction with ideas about artificial intelligence, provided an avenue through which he could build a beginning theory that explores the question of how visual structure yields meaning to the viewer.

His artficially intelligent, expert system, software program AARON embodies his developing theory of representation. It is built on the assumption that all humans share similar basic cognitive principles which also shape the beginning stage of human art making. Cohen (1979) asserts that all humans in the beginning stage of image-making employ figure and ground, insideness and outsideness, closure, repetition, and symmetry, and the AARON program incorporates these principles (Fig. 2). His (Morbey, 1990) next level of art making embodies representations of things that we observe about us, for example, plants, rocks, and people (Cohen, 1988) (See Figs. 3 and 4). AARON has developed to the point where it can simulate these human art making activities. AARON is based on the scientific concept of 
"modelling," that is, a simulation of a complex system that can be run on a computer in order to observe whether it behaves like the system it is to simulate (Harold and Becky Cohen, 1977). Cohen argues, and I think convincingly, that since people have difficulty believing that the computer program made the art that the AARON model has had a measure of success (Harold and Becky Cohen, 1977).

\section{Implication for Art Education}

The question of how the visual symbol yields meaning to the viewer that resurfaces with Wittkower and that Cohen addresses through his developing theory of representation embodied in the drawing program AARON is a question artists have asked for millennia. Wittkower's inquiry, giving rise to Cohen's proposed resolution in the artificially intelligent AARON program, a program that models what the artist does and thereby constituting a representation of the artist's representational acts, elucidates an important question of art makers and art educators, and those who develop theory concerning art and how to teach others abut art making and art reading. These two activities, the making and reading of visual imagery, comprise the main concerns of teaching how to teach about art.

The AARON model presents insight into the nature of art making processes by providing, through computer artist AARON, an observable example of what an artist does in making art, beginning with the "basic cognitive principles" of figure/ground, insideness/outsideness, closure, repetition, and symmetry, and advancing to a more sophisticated level in the rendering of the human like figure. We can view, at arm's length, AARON's art making through the program code, a hidden mental activity unavallable to the individual art maker. Those giving instruction in the teaching of art making and art reading can look to AARON for concepts about art making: an explanation of what an artist needs to know about the world and about representation in order to make a plausible representation, from the scribbles of small children to more sophisticated levels; and a further understanding regarding the nature of image-mediated transactions, that is, the minimum condition for a set of marks to function as an image.

The AARON model provides a notable example of interdisciplinary artistic activity that is necessary for the teaching of art in an age of telecommunications. Beverly Jones (1983) argued in a paper given at the 1983 Ohio Art Education Leadership Conference that "the significance of technology in art education is a timely and important issue which must be addressed." As art educators living in an information society we are challenged to crtically examine and responsibly incorporate computer technology at every border where art and education cross. Our children, at very young ages, are socialized into the computer culture through Nintendo and video games. Research studies indicate that the making of computer graphics can enrich art and aesthetic education (Freedman, 1991; Freedman \& Relan, 1992). This requires that classrooms be equipped appropriately, 
when financially possible, with state-of-the-art computer equipment. More importantly, curricular development needs to incorporate a considered use of computers and call for pertinent training for teachers that involves technical skill development and understanding of issues affecting the computer and education. An additional problem concerning computer learning in art education is the teacher's fear of the technology (Bowers, 1988) which appropriate training could alleviate. Historically, the inclusion of computer related art in art educational programs has not met with an easy reception. Art educators, knowledgeable in questions concerning aesthetic value, are not applying this knowledge to the study and development of new technologies (Jones, 1983).

If one is to teach well, then one needs to teach towards the future. This premise suggests that art education needs to encompass our current place in history, critically (?) embracing contemporary cultural and artistic issues, and working towards a future, rather than only replicating that which was done in the past. As art educators we can look beyond the traditional formats of the classroom, museums, galleries, and publications, to innovative and interactive approaches, as observed in Cohen's AARON model, to teaching about art making interlinked with computer technology.

\section{References}

Barrett, T. (1990). Criticizing photographs. Mountain View, California: Mayfield Publishing Company.

Bowers, C. A. (1988). The cultural dimensions of educational computing, understanding the non-neutrality of technology. New York: Teachers College Press, Columbia University.

Bowness, A. (1983). Foreward. Harold Cohen. London: The Tate Gallery, 5.

Cohen, $H$. (1992). Correction and comments on the text. Unpublished commentary on M. L. Morbey, From canvas to computer: Harold Cohen's artificial intelligence paradigm for art making (Doctoral dissertation, The Ohio State University, 1992). Dissertation Abstracts International, 1992.

Cohen, $\mathrm{H}$. (1988). How to draw three people in a botanical garden. Proceedings of the American Association for Artificial Intelligence, 846-855.

Cohen, H. (1986). Personal interview, November 17, 1986.

Cohen, H. (1979). What is an image? Proceedings of the Sixth International Joint Conference on Artificial Intelligence, 10281057. 
Cohen, H. and B. Cohen (1977). Harold Cohen. Amsterdam: Stedelijk Museum.

Compton, M. G. (1983). Harold Cohen. London: The Tate Gallery, 19-23.

Freedman, K. (1991). Possibilities of interactive computer graphics for art instruction: A summary of research. Art Education 44 (3), 41-47.

Freedman, K and A. Relan (1992). Computer graphics, artistic production, and social processes. Studies in Art Education 33(2), 98-109.

Jones, B. J. (1983). Understanding the significance of technology in art education. Paper presented at the Ohio Art Education Leadership Conference, 1983.

Morbey, M. L (1990). Aaron: Portrait of the young machine as a male artist. Paper presented at the annual meeting of the Universities Art Association of Canada, Montreal.

Negroponte, N. P. (1976). The return of the Sunday painter. Graphical Conversation Theory. 

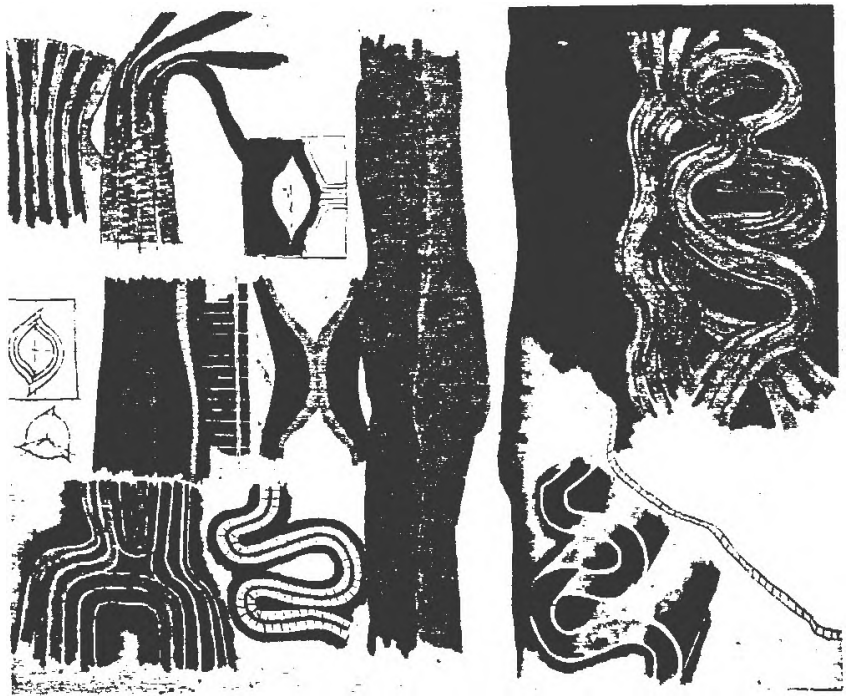

Figure 1. Harold Cohen, Before the Event, 1963, tempera and oil on canvas, $98^{\prime \prime} \times 116^{\prime \prime}$.

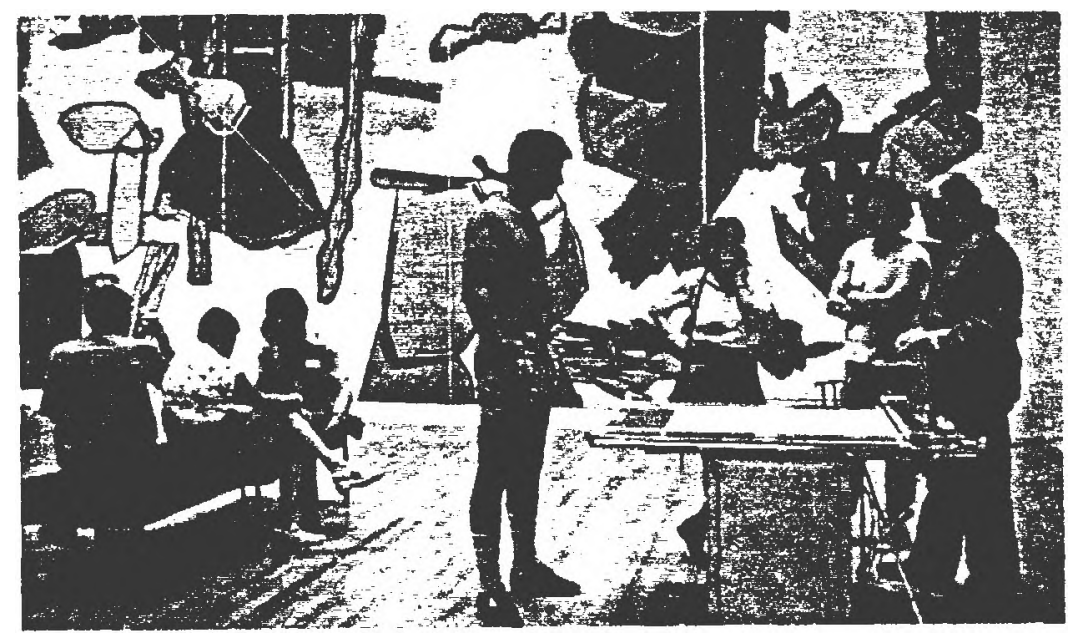

Figure 2. Harold Cohen, Untitled, 1983, computer generated drawing, acrylic on cotton, hand painted, 14 ' $\times 60$ ', Tate Gallery, London 


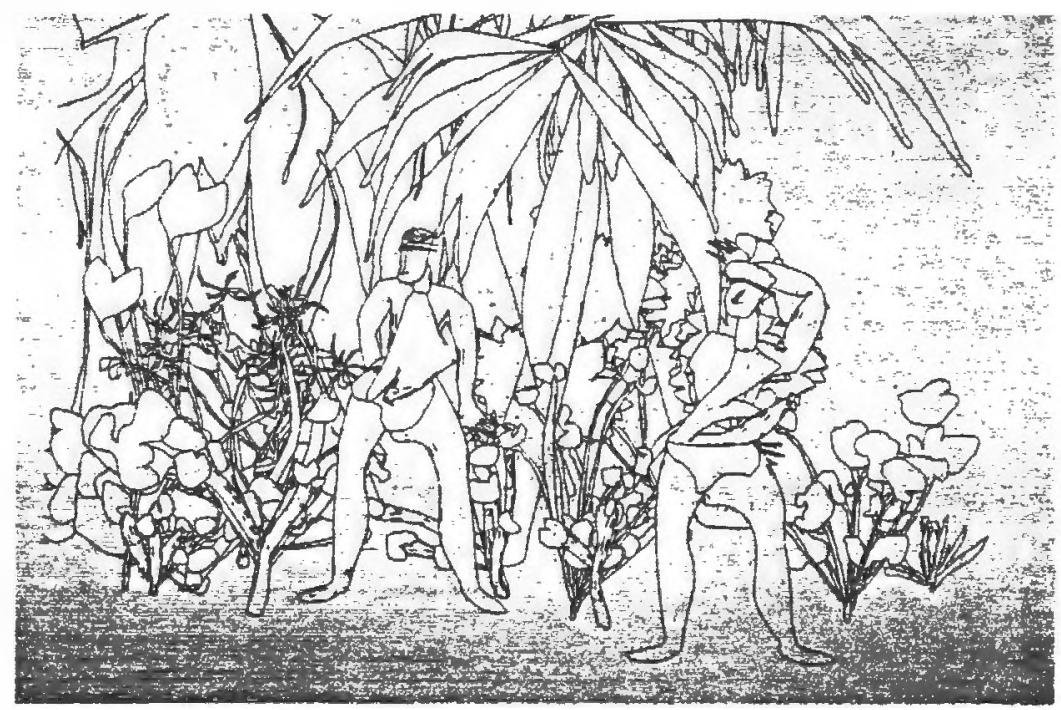

Figure 3. Harold Cohen, Untitled, 1986, computer generated drawing, india ink on paper, 22" $\times 30$ ".

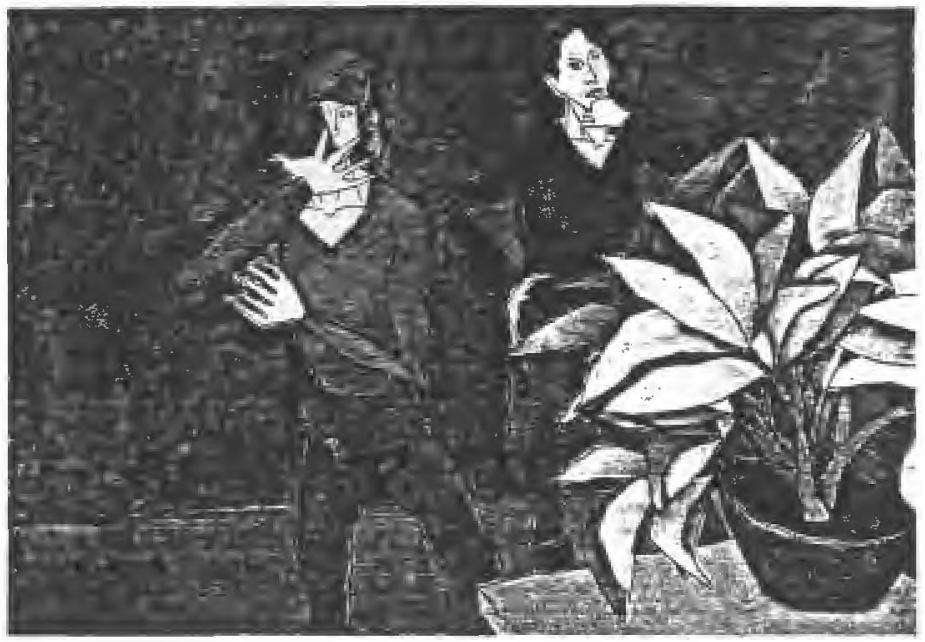

Figure 4. Harold Cohen, Untitled, 1992, computer generated drawing, oil on canvas, $63^{\prime \prime} \times 90^{\prime \prime}$. 